\title{
Action Research On: Improving Participationof Group Members in Group Work, in Case of Mathematics Department, Bule Hora University
}

\author{
Kumera Takele Yadeta \\ Department of Mathematics, Bule Hora University, College of Natural and Computational Science, Bule Hora, Ethiopia \\ Email address: \\ kumeratakele2015@gmail.com \\ To cite this article: \\ Kumera Takele Yadeta. Action Research On: Improving Participationof Group Members in Group Work, in Case of Mathematics Department, \\ Bule Hora University. Mathematics Letters. Vol. 6, No. 2, 2020, pp. 6-12. doi: 10.11648/j.ml.20200602.11
}

Received: June 13, 2020; Accepted: June 23, 2020; Published: August 10, 2020

\begin{abstract}
Group work is defined by as a cooperative process that allows people to achieve extraordinary results also explain that a group has a common goal or purpose where group members can develop effective, mutual relationships to achieve team goals. The problem identified is less participation of members of the groups is the common problem observed in section Mathematics students at Bule Hora University. Thus, the researchers were motivated to conduct this study to recognize root causes of real problem and to give immediate curative solutions. The objective of this study is to identify problems that lead to poor participation of group members in group work. And to identify poorly participating individuals from the group. The role of effective uses of group activities as a teaching method can promote the students learning experience and help teachers' to introduce and implement new teaching techniques. We believe that the level of students' participation in group will be strengthened if they are evaluated on the basis of individual contribution to all courses than in a single course alone as well as by circulating the group leader and random assigning of the presenters.
\end{abstract}

Keywords: Co-operative Learning, Collaborative Learning, Group, Group Work

\section{Introduction}

\subsection{Background of the Study}

Teachers and administrators must be able to identify clearly what techniques are effective at improving students` learning, which ones are not, and how to develop a set of successful instructional practices based on that knowledge [1].

Research is not typically something that teachers think about as part of their regular planning regime. Many teachers are so focused on getting through each day that the mere thought of trying to incorporate research into their professional practice may seem daunting and unrealistic. That may be true for traditional forms of research driven by quantitative and qualitative data analysis; those types of research commonly are very involved and formal, often taking many months and even years to complete. Sample sizes typically need to be large (particularly with quantitative designs). Results are shared usually in the form of scholarly writing through peer-reviewed journals or in research-focused professional conferences [13].

Action research, on the other hand, presents a more user-friendly, practical approach to conduct research. Using this model, which is generally less formal than other types of reseabefrch, teachers and administrators conduct research for one main purpose: to improve teaching and learning [18].

Action research can involve a single teacher or a collaborative team of two or more teachers working together to focus on a mutual topic. Action research projects can take on an even larger scope by involving all teachers within a specific grade level, a particular department, or an entire school [21].

The intend of basic investigate is the expansion of hypothesis and that of practical investigate is on its universal submission while the action research is paying attention on instantaneous submission of hypothesis. Action research located its importance on the result of a crisis here and currently in a limited location. It is a regular technique for solving instantaneous trouble or creation practices improved. Action research is disturbed with the real problem faced by the 
practitioners, followed by attempts made to find solutions of the problems. It is bendable and conducted in familiar contexts to take development in the obtainable circumstances. The purpose of action research is both problem-solving as well as corrective. The intention of action research, by teacher for instance, will be to recognize troubles and then to recover classroom practices by himself or herself. For instance, as a teacher in a primary school you may come across some children in class who face certain difficulties in learning English despite your most excellent efforts. The circumstances is so explicit that the solutions are not obtainable from many sources. As a teacher you have to recognize the causes and supply counteractive measures.

The attitude of action research is not as careful as that of pure or applied research, the individual facing the difficulty, the teacher or superintendent, can carry out it himself. But it may be noted that action research does be appropriate scientific method to answer real-life problems and helps in bringing a huge development in teachers' individual judgments and decisions [4] Another major difference between the action research model and traditional forms of research is sample size; it is possible to conduct action research with a single student, if necessary. Further, the way results are shared can vary from traditional research.

Though sharing results could involve formal publication in journals or presentations at conferences, reporting might consist of much less formal means such as faculty meetings, professional development workshops, or publication on the school district's Web site. Moreover, an action research project can span only a few weeks, or it can last an entire school year and beyond [15].

A group is a collection of people with different abilities, talents, experience, and backgrounds who work together on a common task, where each member works mainly for their own benefit [11].

Group work is defined by [17] "as a cooperative process that allows people to achieve extraordinary results". [6] also explain that a group has a common goal or purpose where group members can develop effective, mutual relationships to achieve team goals. Group work replies upon individuals working together in a cooperative environment to achieve common goals through sharing knowledge and skills.

With the shift from a predominately instructivist to constructivist pedagogy the need for tertiary educators to use a variety of teaching strategies and methods is becoming increasingly important. Learning designs need to incorporate student-centered team based learning pedagogy such as project-based, case-based, inquiry-based and problem-based scenarios [14].

Students need to be immersed in learning environments that promote real learning in real contexts. Groups and group work help to promote deep learning that occurs through interaction, problem solving, dialogue, cooperation and collaboration [9]

Recent changes in Higher Education have brought about a cultural shift and led to a review of and reflection about pedagogy [7]. Part of this reflection centers on the move towards widening participation, and the issues involved in accommodating greater numbers, and a greater diversity of students into universities. Ever increasing class sizes, modular frameworks, lifelong learning and an emphasis on skills development have been underpinned by the introduction of student centered learning and an increasing use of group work as a learning vehicle to deliver the educational experience.

The use of groups and teams in the workplace has led employers as well as academics to recognize group work as a key skill. It is, therefore, vital that prospective employees acquire the skills of group work early in their academic lives and this is why it is increasingly being used as a vehicle to promote learning in University courses [2].

An improved knowledge of group work will enable students to be more effective during their studies and, subsequently, in organizational life. Groups are the 'building blocks' of organizations; employees have to work with other people on projects to complete tasks; they must deal with diversity to enable them to carry out their duties. The overwhelming reason for the use of groups in organizations is that they improve performance and that is why students need to understand the intricacies of group work. Thus, the more experienced students become in the skills of group work, the more effective and efficient they will be in organizations of the future. As a consequence, it is incumbent upon Universities to develop group work skills in students.

Group work is regularly used as an assessment vehicle but, while students get plenty of experience of working in groups, it is less common for them to receive instruction in how to benefit from group work. Probably because of the pressures to deliver subject content, students are, in many cases, left to develop group skills without any explicit guidance on their development [8].

Groups are a fact of organizational life. It is virtually impossible to escape group work in almost any facet of life and higher education is no exception. An advantage for tutors is the opportunity to use group work to encourage and enable students to take responsibility, thus enhancing the ability to complete a task and deal with the issues involved in the process. In a group learning environment, the members can learn to respect individual members' abilities, to accept differences, diversity and differing involvement and work together to enhance each other's contributions [9].

According to [9], there are many reasons for using group work with students, some of which are positive and others less so. The argument for group work is very seductive, as suggested by some of the reasons put forward for adopting it as a teaching method:

1) The output of the group is usually more than the sum of individual effort;

2) Group efforts at problem-solving are more effective than individual efforts;

3) More ideas are generated;

4) Interpersonal and group working skills are developed;

5) Collaboration leads to effective performance;

6) Knowledge and learning are shared;

7) It develops workplace skills.

The academic setting provides students with the 
opportunity to develop skills which ultimately can be transferred to the workplace. The learning environment can be structured so that it is non-threatening and students can experiment with different types of behavior. This will enable them to understand the various elements of group work and to recognize that organizational problems are relatively complex and not amenable to right or wrong answers. Group work permits students to work collaboratively and deal with more complicated problems than any individual could do on his/her own. A major benefit of group work, which students will experience and tutors can observe, is group synergy, where the output of the group effort is more than the sum of the individual input [12].

Working in groups provides students with the opportunity to discuss and refine their understanding of complex issues, solve problems, apply their knowledge, practice skills, and reflect about feelings and what has been learned. They may feel more engaged with the process of learning, rather than being a passive recipient of the tutor's 'wisdom' and this perception can promote participation, exploration and analysis of ideas [20].

As it has been indicated in [20] there are always potential problems and difficulties of working with groups in an educational setting. It is quite usual for students to dislike some aspects of group work. They may feel frustrated because less effective group members are diluting individual effort. Alternatively, there may be uncomfortable peer pressure to work harder or to meet deadlines. It is important for students to experience and deal with these types of behaviors and to work through associated feelings as part of the learning experience.

\subsection{Statement of the Problem}

Given the emphasis on group work in academic settings, it is important to understand student attitudes towards group work. When students work together in a group, they usually split the task into small, separate pieces; each group member then works on their own small piece and, at the end, the separate pieces are joined together. The main advantage gained is division of labor. The disadvantages include: a group member not completing their task on time, the responsibility for assembling the final product or for completing the entire work falls on the shoulder of one person or few members of the group, members do not necessarily contribute to each other's work, and members do not usually understand what the others have done at all. This less participation of members of the groups is the common problem observed in Mathematics students at BuleHoraUniversity. Thus, the researchers were motivated to conduct this study to recognize root causes of real problem and to give immediate curative solutions.

\subsection{Objectives}

1) To identify problems that lead to poor participation of group members in group work.

2) To propose ways to identify poorly participating individuals from the group.
3) To improve teaching and learning.

4) To take relevant and immediate actions to solve the problems.

\subsection{Significance of the Study}

After successful completion of the work, the relevant remedies found to be paramount importance to improve and facilitate the active learning activity to which it paves the way students can learn at their own pace. The information's and findings from this study will open the door for the future collaborative action research studies or projects that will continue the cycle of teaching and learning process.

\section{Methodology}

\subsection{Description of the Study Area}

Bule Hora University is found in Oromia region in Southern Ethiopia which is about $467 \mathrm{kms}$ from Addis Ababa which is the capital city of Ethiopia.

Methods of sampling and sample size

The target populations of the study are second year Mathematics section one students. To select the samples from the target group random sampling methods were applied. From 2 groups 1 groups were selected randomly and filled the prepared questionnaires. Among 57 (32 of them were females and 25 males) students of the section 52.63\% (1-groups) represented as a sample the section. There are four Mathematics teachers offering Mathematics courses in this academic semester. So for this reason sampling is not applied for them since they are few in number. The four instructors were selected and filled the questionnaires prepared for them.

\subsection{Data Sources}

To achieve the objectives of this study I used only the primary data. The main sources of data for this particular study are:

1) Mathematics Department.

2) Course delivery teachers.

\subsection{Data Collection Tools}

I, the researcher of this work used questionnaires and interview as a data collecting tool. Open and closed ended questions were prepared for both students and course delivery teachers. For students, questionnaires were prepared in Amharic for clarity, whereas, questions for teachers were prepared in English.

\subsection{Methods of Data Analysis}

All the information's collected using the above techniques were analyzed and interpreted by using qualitative and quantitative methods. Information's were arranged in their order of importance; the data that are obtained from the respondents were tabulated and information's gathered through interview were also analyzed. 


\section{Data Presentation and Interpretations}

The role of effective uses of group activities as a teaching method can promote the students learning experience and help teachers' to introduce and implement new teaching techniques. Researchers have indicated that children need to be trained in co-operative learning in a purposeful and systematic way if they are to be able to use them effectively in their interactions with their peers. Linking group members together and goal interdependence are key elements of successful co-operative learning, ensuring that they are trained in the interpersonal and small group skills needed to promote positive interactions [3].

\subsection{Data Analysis from Students`View}

\subsubsection{Students Attitude towards Co-operative or Group Learning}

As we confirm that students are not that much interested to learn from their peers. This is because students are fear of when they are criticized by their own classmates. Some of the students may also tied passively on group tasks and they need to stand over the shoulders of very few members or on only a single individual while teachers ordered them to do together. As tabulated in the table below, $20 \%$ of the students were eager to rate highly towards co-operative learning, and $50 \%$ of the respondents entertain in group activities in a medium manner. Among the respondents $30 \%$ were very passive to participate on collaborative tasks. Students have requested to justify reasons why not interested in group tasks as an individual. They have reason out that, the group leader students are the better performers and they not let low level learners to do tasks and the better students do not waste time to activities with low levels of their peers.

Table 1. Students` interest towards cooperative/ group learning.

\begin{tabular}{llll}
\hline \multirow{2}{*}{ № } & \multirow{2}{*}{ Responses } & \multicolumn{2}{l}{ Number and \% of Respondents } \\
\cline { 3 - 4 } & & № & Percentage (\%) \\
\hline 1 & High & 6 & 20 \\
2 & Medium & 15 & 50 \\
3 & Low & 9 & 30 \\
4 & Very low & 0 & - \\
\hline
\end{tabular}

The former idea is supported by [15], in a sense is that, the group members believe that they will have more marks from the group task if higher achievers participate only. This also saves the time of talent students waste for directing students to the core concept of the task.

Some students also respond that teachers are not willing to pave the way in which students can learn at their own pace from the groups. Students also jot down lack of initiations from their classmate (group members) as a decisive factor that rate their interest very low towards co-operative learning.

\subsubsection{Students Level of Involvement in Group Activities}

As a teacher, we cannot despite, the active involvement of some students that do have an immense role in all group works. In this work, from the total respondents, $16.67 \%$ have a full flagged responsibility in their groups to always avail in all activities. This might be due to the presence of very few number of students that can stand by their own and capable to accomplish given tasks successfully than the other members of the group. The other reason may be some students need their involvement to have a positive feedback from the teachers if there is a presentation for the task. Group participant student members are more confidential while they assigned to present group works in front of teachers and students than the non-involvers [20]. $43.33 \%$ of the respondents indicated they involve in group activities sometimes. This may be due to students need to partition activities and some students activated in one course and others on the other. And some students may perceive some teachers are not series on individual involvement of the tasks.

Table 2. Participation of students in group assignments and activities.

\begin{tabular}{llll}
\hline \multirow{2}{*}{ № } & \multirow{2}{*}{ Responses } & \multicolumn{2}{l}{ Number and \%o of Respondents } \\
\cline { 3 - 4 } & No & Percentage (\%) \\
\hline 1 & Always & 5 & 16.67 \\
2 & Usually & 13 & 23.33 \\
3 & Sometimes & 7 & 43.33 \\
4 & Never at all & 5 & 16.67 \\
\hline
\end{tabular}

As we have confirmed from the above table, $23.33 \%$ of the respondents participate near frequently. However, $16.67 \%$ of the respondents respond that they ever and never involves in group tasks. This might be tasks may not clear to students and may not well aware about the use of co-operative learning. On the other hand teachers may not employ some techniques to select out non-participants from the group during assessments. Less reactive behaviors among the group members lead some students not actively participate in group works [8].

Table 3. Students witness whether the teachers employed some methods to identify participants and non-participants.

\begin{tabular}{llll}
\hline \multirow{2}{*}{ № } & \multirow{2}{*}{ Responses } & \multicolumn{2}{l}{ Number and \%o of Respondents } \\
\cline { 3 - 4 } & & № & Percentage (\%) \\
\hline 1 & Yes & 18 & 60 \\
2 & No & 12 & 40 \\
\hline
\end{tabular}

We know that, students ` concerns about the effluence of the mark on their overall grade my well more pronounced with group work than for other types of assessments, due to the perception that this influence is beyond their control. This overall effect is handled by the teacher if and only if he/she identifies participation levels of his/her students in group activities. $60 \%$ of student respondents point out that their teacher devise mechanisms to identify non participant passive students among the group members. Teachers may use various mechanisms to come up with all identification methods. Among these; creating awareness on the use of group activities, making an open defense for individuals during evaluation, by informing all students to put their hand writing on the group activity and by grouping students in accordance with students level of understanding in the group were some of the methods that the students suggested. 
Table 4. Effects of poor participation observed on the group.

\begin{tabular}{llll}
\hline \multirow{2}{*}{$N$ Eo } & \multirow{2}{*}{ Effects of poor participation } & \multicolumn{2}{c}{ Number and \%Respondents } \\
\cline { 3 - 4 } & $\mathbf{N o}$ & Percentage (\%) \\
\hline 1 & $\begin{array}{l}\text { Less knowledge acquire of the } \\
\text { course }\end{array}$ & 10 & 33.33 \\
2 & $\begin{array}{l}\text { Poor grade scoring in the } \\
\text { course }\end{array}$ & 7 & 23.34 \\
3 & $\begin{array}{l}\text { Frustrations during exams } \\
4\end{array}$ & 5 & 16.67 \\
Stage anxiety during & 8 & 26.66 \\
\hline
\end{tabular}

When some group members are highly motivated to achieve high grades, though the others were content with merely just gaining only a pass mark with minimal efforts, this miss match of expectations may result in many problems and frustrations among the group members [19]. As a dilemma of poor participation, poor participants in group activities acquire less knowledge from the course. $23.34 \%$ of the respondents suggest that they were score poor grades from the course, $16.67 \%$ and $26.66 \%$ of the respondents also respond that they were highly exposed for high frustrations during exam periods and stage anxiety during presentations, respectively while they did not participate in group tasks.

\subsection{Data Analysis from Teachers`View}

Table 5 Percentage of teachers including group activity in the assessment modality.

\begin{tabular}{llll}
\hline \multirow{2}{*}{ № } & \multirow{2}{*}{ Teachers response } & \multicolumn{2}{l}{ Number and \%o of Teachers } \\
\cline { 3 - 4 } & & № & Percentage (\%) \\
\hline 1. & Yes & 4 & $100 \%$ \\
2. & No & 0 & \\
\hline
\end{tabular}

Table 5 revealed that the entire participants used to full fill the questioners were responded as they were included collaborative learning in their assessment modality. This implies that almost all biology teachers were implemented active learning methods in the teaching learning process to facilitate cooperative and interdependence work among students.

Table 6. Participation level of students in the group activity.

\begin{tabular}{llll}
\hline \multirow{2}{*}{ № } & \multirow{2}{*}{ Teachers response } & \multicolumn{2}{l}{ Number and \% of respondents } \\
\cline { 3 - 4 } & & № & Percentage (\%) \\
\hline 1. & Yes & 1 & $25 \%$ \\
2. & No & 3 & $75 \%$ \\
\hline
\end{tabular}

Table 6 depicted that $75 \%$ of the teachers indicated that more than half of the students were poorly participated in the group activity both in and outside of the class. The main reason for poor participation of students in group work was explained as frustration because less effective group members and uncomfortable peer pressure to work harder according to [20].

Table 7. The role of group activity in improving knowledge and skills of students.

\begin{tabular}{llll}
\hline \multirow{2}{*}{ № } & \multirow{2}{*}{ Response } & \multicolumn{2}{l}{ Number and\% of participants } \\
\cline { 3 - 4 } & & № & Percentage (\%) \\
\hline 1. & Yes & 4 & $100 \%$ \\
2. & No & 0 & \\
\hline
\end{tabular}

Table 7 showed that $100 \%$ of the teachers were reflected that the collaborative work among the students allows each individual in a group to acquire new idea and information from themselves. The work of [10] on social interdependence and cooperative learning in education also revealed similar result with the current study conducted in $2^{\text {nd }}$ year section 1 Mathematics students at Bule Hora University.

Table 8. Learning outcomes acquired from group activity.

\begin{tabular}{llll}
\hline \multirow{2}{*}{$№$} & \multirow{2}{*}{$\begin{array}{l}\text { Types of knowledge } \\
\text { acquired }\end{array}$} & \multicolumn{2}{c}{ Number and \% of respondents } \\
\cline { 3 - 4 } & № & Percentage (\%) \\
\hline 1. & Cognitive & 1 & $25 \%$ \\
2. & Psychomotor & - & - \\
3. & Attitude & 1 & $25 \%$ \\
4. & All rounded & 2 & $50 \%$ \\
\hline
\end{tabular}

Table 8 Depicted that $25 \%, 50 \%$ and $25 \%$ of the teachers reflected that the group activity provides a change in a knowledge, attitude and all rounded domain towards students thought respectively. This result was in agreement with the study conducted by [20] on the processes and outcomes of team learning that revealed working in groups provides students with the opportunity to discuss and refine their understanding of complex issues, solve problems, apply their knowledge, practice skills, and reflect about feelings and what has been learned.

\section{Actions Proposed to Be Taken}

After data has been analyzed, research questions have been answered, and conclusions have been drawn, it is time to draft a plan of action for the future and reflect on the experience [16].

There are several strategies that can be used to improve students' participation in group work. For instance, [5] has summarized several strategies to be used to make group work effective. Some of the strategies are:

1) Establish groups of small size (usually not more than six).

2) Forming heterogeneous group.

3) Determine what to be assessed; the process or the product.

4) Create group tasks that require interdependence and fair distribution of labor among the members.

5) Circulating the group leaders among the group members random selection of presenters.

6) Devise adequate mechanism to assess the contribution of each member in the group.

However, this group of researchers selected six strategies to be implemented to improve individual participation in group work. The strategies were identified on the basis of the teacher researchers' experience, interview with teachers and questionnaire from the students. The strategies are:

1) Communicating students about the relevance of the group work.

2) Establishing groups of small size and heterogeneous group.

3) Giving clear direction about the group work. 
4) Random assignment presenters.

5) Circulating the group leader.

6) Devising fair assignment technique that considers the contribution of each member.

\section{Actions Implemented}

The strategies identified by the team to improve students' participation in group work were implemented on the second year section 1 Mathematics Students. First, the students were communicated about the relevance of group work for their learning. Second, the students were assigned randomly into six groups of five members (small group) to keep the balance between each group. Third, the students were given clear direction about group work thereby they can know what is expected of them. Fourth the presenters were randomly assigned among students with circulating group leader. Finally, an assessment technique that considers the contribution of each group was implemented.

During the implementation of the final strategy, both the process and the product of the group were considered. Accordingly, the students in a group were awarded equal marks for the product they submitted. The mark constitutes $33.33 \%$ ( 5 marks) of the total marks (15 marks). The students were also awarded different marks based on their individual contribution in the group process. The students were asked to answer three questions regarding their group work in written form (i.e. quiz) which was evaluated from 5 marks (33.33\%). For the remaining $33.33 \%$ (5 marks) the students were required to present their group work.

After the presentation is completed, each student was requested to answer some questions forwarded by the teacher and members of other groups based on what is presented by his/her respective group.

\section{Evaluation of the Changes}

The teacher researchers tried to see whether the selected strategies have brought changes in students' behavior (participation) in group work or not. To this end, when the group work is completed and submitted, the students were required to answer some questions such as state the title (topic) of their group work, list the names of members of their group and outline major points that they have discussed in their group work presented in the form of quiz attached with the test they took before the presentation.

In addition, the students were also requested to present their group work to their class thereby the contribution of each member of a group is determined on the basis of his/her response to questions raised mainly by the teacher and by the members of other groups as well.

Finally, it was observed that the majority of the students $73.33 \%$ (22 out of 30 students) were able to answer the questions presented in the form of quiz prior to the presentation to check individual participation in group work. The proportion of students who answered oral questions following each presentation was also higher, $80 \%$ (24out of 30 students). This indicates that the participation of the students in group work is improved after the selected actions or strategies were implemented.

\section{Conclusion}

Thus, we can say that the strategies implemented have brought change in students' attitude (participation) in group work. We believe that the level of students' participation in group will be strengthened if they are evaluated on the basis of individual contribution to all courses than in a single course alone as well as by circulating the group leader and random assigning of the presenters.

\section{Recommendations}

In this action research we have learnt that it is possible to improve students' participation in group work by implementing different strategies such as communicating the relevance of group work for learning, assigning students randomly into groups of small size, random assigning of presenters, circulating the group leader, giving clear directions about group work and assessing students based on individual contribution.

In light of the evidences in this study, we would like to recommend teachers to implement the strategies that we implemented on second year section 1 Mathematics students and improved their participation on group work.

\section{Acknowledgements}

The authors wish to acknowledge the authors for providing a published different Article review publication to the first author during 2000s to carry out this Article at Bule Hora Un iversity, Oromia regional state, Southern Ethiopia. The critical review and comments offered by Mr. Million Chimdessa and Mr. Kasim Rabiyo were acknowledged. The assistance given from by Mr. Negeri Negese and Mr. Boru Wachu to collect the literature from different source is acknowledged.

\section{References}

[1] Airasian, P. W. (2001). Classroom assessment: Concepts and applications, 4th ed. Boston: McGraw-Hill.

[2] Atkins, M. (1999). 'Oven-ready and Self-Basting: Taking Stock of Employability Skills', Teaching in Higher Education, 4, 2, 267-280.

[3] Battistich, V. and Watson, M. (2002). Fostering social development in preschool and the early elementary grades through co-operative classroom activities. Journal of social development. 2 (5), 10-15.

[4] Corey, S. M. (1953). Action research to improve school practices. New York: Teachers College Press, Development, 6 (2), 118-127.

[5] Devis (1993) Tool for teaching San Francisco small group of work 
[6] Harris, P. R., \& Harris, K. G. (1996). Managing effectively through teams. Team Performance Management: An International Journal, 2 (3), 23-36.

[7] Harvey, L., Locke, W., Money, A. (2002). Enhancing Employability, Recognising Diversity, Universities UK-CSU.

[8] Honey, P. \& Mumford, A. (1986). A Manual of Learning Styles, 2nd Edition, Maidenhead.

[9] Jaques, D. (2000). Learning in Groups, A Handbook for Improving Group Work, 3rd edition, Kogan Page, London.

[10] Johnson, D. W., \& Johnson, R. T. (1995). Social Interdependence - Cooperative Learning in Education. InB. Bunker \& J. Z. Rubin (Eds.), Conflict, Cooperation, and Justice (pp. 205-251). San Francisco: Jossey-Bass Publishers.

[11] Lencioni P. M. (2003). The Trouble with Teamwork Leader to Leader Institute Summer 2003 pp 35-40.

[12] Martin, V. (2002). 'Group Working', Nursing Management, 8 , 9, 28-31.

[13] Mason, R. D., D. A. Lind, and W. G. Marchal. (1991). Statistics: An introduction, $3^{\text {rd }}$ ed. San Diego: Harcourt Brace Jovanovich.

[14] Oliver, R. (2001). Developing e-learning environments that support knowledge construction in higher education. Presented at the 2nd International We-B Conference, pp. 407-416. Perth, Western Australia.

[15] Ross-Fisher, R. L. (2008). Action Research to Improve Teaching and Learning. Kappa delta pi record • summer 2008: 160-164.

[16] Sagor, R. (2000). Guiding school improvement with action research. Alexandria, VA: Association for Supervision and Curriculum Development.

[17] Scarnati, J. T. (2001). On becoming a team player. Team Performance Management: An International Journal, 7 (1/2), $5-10$.

[18] Slavin, R. E. (2006). Educational psychology: Theory and practice, 8th ed. Boston: Allyn \& Bacon.

[19] Tarricone, P. \& Luca, J. (2002). Successful Team work: A Case study, Edith Cown University, Perth, Australia.

[20] Van Offenbeek, M. (2001). Processes and outcomes of team learning. EuropeanJournal of Work and Organizational Psychology, 10 (3), 303-317.

[21] Watts, H. (1985). When teachers are researchers, teaching improves. Journal of Staff. 